\title{
GOING WITH THE FLOW: The State of Contemporary Studies of Water Management in Latin America
}

\author{
Paul Trawick \\ Cranfield University, Silsoe, England
}

ANTOLOGÍA SOBRE PEQUEÑO RIEGO, VOLUMEN II: ORGANIZACIONES AUTOGESTIVAS. Edited by Jacinta Palerm Viqueira and Tomás Martínez Saldaña. (Mexico D.F.: Plaza y Valdés, 2000. Pp. 469. \$15.00 paper.)

WATER RIGHTS AND EMPOWERMENT. Edited by Rutgerd Boelens and Paul Hoogendam (Assen: The Netherlands: Koninklijke Van Gorcum BV, 2002. Pp. 255. a25.00 cloth.)

WOMEN AND WATER MANAGEMENT: THE LATIN AMERICAN EXPERIENCE. Edited by Cecilia Tortajada. (New York: Oxford University Press, 2000. Pp. 231. \$27.95 cloth.)

WATER AND POWER IN HIGHLAND PERU: THE CULTURAL POLITICS OF IRRIGATION AND DEVELOPMENT. By Paul Gelles. (New Brunswick, NJ: Rutgers University Press, 2000. \$52.00 cloth, \$22.00 paper.)

The study of irrigation and water management has moved steadily into the foreground during recent decades and now holds a singular place in the field of international development in Latin America and other parts of the world. The recognition that irrigation is much more than a technical problem, and that the main challenges are social, political, and moral, has allowed scholars to shift the focus of analysis and correct the shortcomings that arose from viewing it solely in technological and agronomic terms. Misconceived policies such as centralized administration by the State are being cast aside, having had the opposite of their intended effect, as are the inappropriate models that have shaped existing water laws and dominated such conventional approaches to resource management, which were heavily influenced by Garrett Hardin's theory of the "tragedy of the commons." After enjoying a brief heyday among policymakers, the most fashionable of the new approaches, turning decisions about water allocation over to 'the market'-Hardin's other proposed solution-has been challenged so fiercely by the public in Ecuador, Bolivia, and Peru 


\section{Latin American Research Review}

that its main proponent and the most powerful player in the globalization game, the World Bank, is now said to be on the verge of becoming a "privatization agnostic." All of this comes at a time when governments throughout Latin America are searching for a way to foster effective local management of the resource, within a decentralized watershed-based model, in order to get out of the "business" themselves-an about-face that is partly due to the resounding failure of state control but also reflects their forced abandonment of the social sector under programs of structural adjustment. Each of the four volumes under review here embraces the challenge of such a unique historical moment, examining the results of case studies of successful "self-management" at the local level and trying to draw conclusions that help to move the discourse about theory and practice onto new ground. This is especially timely given the impending water crisis that threatens most of the world, particularly the "developing" countries, and the growing awareness that the resource most vital for human life is scarce, is becoming scarcer every day, and is increasingly likely to promote conflict.

The books must be viewed against the background of some relatively new insights into irrigation that inform them, especially the well-demonstrated ability of local people in a great many communities throughout the world-in Mexico, the Andes, Spain, Sri Lanka, India, Nepal, Bali, the Philippines-to work out sustainable ways of managing the resource on their own. Indeed, in the literature on the water commons there now seem to be almost as many cases of success, an achievement that Hardin thought to be impossible, as of failure. Yet there seems to be little agreement on whether all of these successful examples have anything basic in common, such as rules and design principles that could help to reshape policy and perhaps modify existing laws so as to strengthen people's capacity for local self-management. There is dispute regarding the small-scale, autonomous, often "indigenous" peasant communities where such ability has been most clearly documented, and as we will see below, also with respect to large-scale canal systems composed of multiple communities, where internal differences and opposed interests are more prevalent and where far fewer examples of success have, up until now, been found.

Thankfully, the latter are the focus of many of the studies included in the anthologies on Mexico and the Andes, and that is an invaluable contribution. However, the books diverge on the nature of possible policy implications, and they seem to be at a classic "post-structuralist" impasse in the debate. This is understandable, given the diversity that seems, on the surface, to be evident among successful irrigation systems of both the single and multi-community types. However, the dispute also arises from an issue that is less empirical than epistemological, and that is the validity and value of generalization itself. 
The volume on Mexico, edited by Palerm Viqueira and Martínez, is noteworthy for its exclusive focus on largely endogenous, bottom-up forms of multi-community organization. It deals with the plight of communities (ejidos, villages of small proprietors, and ex-haciendas) that were formed through the redistribution of land and water during Mexico's agrarian reform, initiated in 1915-1917. Some of these have struggled ever since to gain autonomy and to maintain control over their water in the face of the government's persistent and often inept interference. The book documents, in seven case studies, the ability of different user groups-small-scale juntas de regantes-to work together and find ways of sharing a scarce and unstable resource while resolving the inevitable conflicts that arise, both within and between them. But despite the editors' commitment to useful generalization, the contributors never reveal clearly the basis of such success or the rules and principles that define existing rights, both for the individual and the group, that have proven to be effective in each particular case.

We are, however, given tantalizing glimpses of what such supra-community groups may have in common: the same solution to the challenge of cooperatively running a large-scale system with equity and fairness. This abstract concept often seems to have been defined, in concrete terms, as proportionality among the component groups' water rights and between those rights and their corresponding maintenance duties. Although we cannot be sure, this appears in most cases to be the same institutional arrangement that governs water use within each individual community as well. Such proportionality, if it does indeed exist, would seem to require that the frequency of irrigation also be the same for each local user and each separate junta. In two cases (the Junta de Aguas of San Juan de Teotihuacán, as described by González Huerta, and the Comite de Vigilancia of the Nexapa river, discussed by Guadalupe Rodríguez) we are given enough information to confirm that this basic uniformity has somehow been established. Throughout the book we see evidence too of the struggle to monitor each separate community's water use and maintain some degree of transparency within the over-arching system, but it is not explained how this is done.

The distinct possibility of such basic commonalities persists throughout the book, even in the most anomalous case: the Tehuacán valley (chap. 9 by Campos et al.), where a multitude of local user communities, each exploiting various kinds of water sources (springs, filtration galleries, drilled wells, and diverted runoff from heavy rainfall), utilize a network of interconnected and often overlapping canals. These ancient canals, and the prevailing form of multi-community organization, supposedly allow water shares to be freely traded (i.e., rented, bought, and sold) over a wide area. The authors' description of this apparently vast water market is so sketchy, however, from a functional point of 


\section{Latin American Research Review}

view, as to make one wonder if it is not really an organization of small communal systems, each based on equity as defined above, where money simply provides the means (one of several possible ways) of facilitating and keeping track of small water transfers, which in each case occurs only within a restricted area.

The editors point out that roughly half of Mexico's five million hectares of irrigated land (the most in any Latin American country) are in the hands of small user communities composed of peasants and small proprietors, rather than big landowners and agribusinesses, juntas that have shown this capacity for self-management at both intra- and intercommunity levels. Together, the chapters show that the Mexican government has historically denied legitimacy to self-organized supra-community groups, apparently because of the challenge they posed to the State's authority, and steadfastly refused to acknowledge their ability to manage the water of their own river or the flow of their own springs. For the editors and the volume's contributors, the challenge is to arrive at a general model, based on the principles of successful small-scale irrigation, that can be applied effectively to large-scale hydraulic works, the distritos de riego built and operated by the State during the last century as part of the Green Revolution, which are now being turned over to the local user groups that comprise them. The editors insist that this kind of generalization, based on common rules and principles of local customary law, is possible and should be the point of social science research. But they stop short of doing it in the conclusion and leave it up to the reader, or perhaps to future research. Unfortunately, although the contributors usually outline the history of each multi-community organization, their accounts are largely descriptive without being sufficiently systemic, constantly providing unnecessary detail (the name of every person quoted or the person responsible for any significant decision or event) that ultimately leaves little room for insightful analysis. The book thus documents local success at this level of complexity fairly well, a significant enough accomplishment, but does not explain or account for it.

The Andean volume, edited by Boelens and Hoogendam, is far more sophisticated. It provides a wealth of detail in the seven case studies presented, all of which serves to further the analysis, enhance the reader's comprehension (even for someone not familiar with irrigation) and, in most respects, support the theoretical stance taken by the editors in the introductory and concluding chapters. Probably the most impressive collection and synthesis of case studies of irrigation development ever published-certainly the best on Latin America-focuses exactly where it should, on "individual" water rights: how these are defined in largely autonomous, self-managed peasant irrigation sys-

tems of both the single-community and multi-community types. In most 
of the chapters, the dynamics of this process (and it is a process rather than an event) are revealed clearly because the rights in question have recently had to be redefined. Some kind of major intervention has radically increased-or, in one Chilean study (chap. 9 by Castro-Lucic), decreased-the water supply and usually also the area under irrigation. In most cases, an NGO has designed an improvement project sponsored by a donor agency and carried it out with the local communities' full, often defiant, participation.

Much is revealed by the project outcomes, the arrangements ultimately arrived at for sharing water, and even more by the stories of how the communities got there. "Individual" or household water rights are defined or redefined in the act of constructing or re-building a canal system, which in the Andes are usually very old, dating back to Inca or Pre-Inca times in Peru and Bolivia and at least to colonial times in Ecuador. Today, successful locally-run systems have household allotments of water that are usually proportional, at least in theory, to the area of land irrigated by each family. This arrangement is continually reaffirmed and validated through annual contributions (usually labor but sometimes money instead) to maintaining the infrastructure-investments that, again, are typically required to be proportional to those rights in terms of either the amount of water consumed or the area of land irrigated (basically two ways of measuring the same thing). Exceptions exist, for example in situations where household maintenance duties are equal (the same for everyone despite differences in landholdings and water use), but mainly in communities where internal stratification is relatively limited, and especially where the number of workdays needed for canal maintenance is small. In some cases (Chapter 8 by Claure, Gutiérrez, and Hoogendam; Chapter 11 by Boelens and Doornbos), such strict equality has been decided upon in lieu of proportionality in order to ensure that all members have an equal right to vote and participate in decision-making. However, in most cases this crucial aspect of water rights-equal voting rights-is a given and is not problematic (but see the discussion of gender relations below); and in any case it is usually mandated by national water law.

The book shows repeatedly that any project intended to increase the water supply, either through conservation or by tapping new water sources, will jeopardize existing rights or distort them in some way unless they are either deliberately preserved or explicitly redefined, and we see the community members struggling to ensure that one of these is done. Existing rights must therefore be studied closely beforehand, and any changes in them must be explicitely planned for by any project that seeks to promote sustainable self-management, along with careful definition of any new rights that will be created. Failure to do so, and to work toward a desired end decided upon by the community members 


\section{Latin American Research Review}

themselves, has unfortunately been the rule in the past and nearly always has led to disaster. This outcome usually has reflected the purely technical and agronomic view of irrigation held by project engineers and professionals, a fundamental distortion that the volume's contributors seek to dispose of once and for all. They show that cases where truly "participative" assessment and planning has been carried out by the sponsoring group, either willingly (as in chap. 10 by Apollin) or reluctantly in response to community resistance and protest (chaps. 2 by Gelles, 3 by Gerbrandy and Hoogendam, and 7 by Boelens), have led to successful reorganization and to a sustainable expansion. These examples teach us a great deal, not only about effective interventions but also about the politics of water management, about village social life, and about Andean peasants themselves. That, in brief, is what this extraordinary volume is all about.

In the Andean studies, much more than in the Mexican studies, we see that irrigation and local self-management depend on clearly defined rights, both the old ones and the new ones, and, again, that such rights are defined in terms of "equity," a kind of relative equality. But the editors argue that equity means different things to different people in different historical and social situations. It cannot be prescribed in terms of some basic principle or formula but has to be defined and created dynamically, by the users and user-groups, through contestation and negotiation in each local setting. This process will reflect the diverse values and interests that inevitably exist, even within the most cohesive community; and it can and should be only minimally guided or facilitated by outsiders. Because equity comes in so many varieties, the editors are firmly against the kind of generalization and model building based on "instrumental" thinking advocated in the Mexican volume, arguing that, no matter how such plans are carried out, they are simplistic, outmoded, and prone to project failure. This stance also reflects a clearly stated and rather fashionable aversion to abstract thought. In a lucid analysis and synthesis of the seven case studies - one shaped by the editors' thorough command of the literature and an enormous amount of practical experience-the main concern is to show how outsiders, such as NGO professionals, can empower local people in asserting their autonomy and achieving outcomes that they define as equitable according to their own normative frameworks, sometimes in defiance of the state and national water law. All of the volume's contributors do this very well, showing their commitment to promoting greater equity in projects while also advocating the inclusion of underrepresented or excluded groups.

One of the most timely and unique contributions in this volume is a discussion of gender roles in irrigation, by Boelens and Zwarteveen (chap. 5). It provides a useful complement to Tortajada's edited volume 
on women and water management, covering some of the same ground but in a more theoretically sophisticated way. In both cases the authors show that women can, and do, play a major role in managing the resource, perhaps even the primary one today, and the authors argue that women should be included and allowed to participate, not only as members but also as leaders of water user groups. The latter anthology is composed mainly of programmatic statements advocating general policy changes for various countries, rather than detailed case studies (but see chap. 8 on Mexico by Ávila-García). It bases the argument on the fact that, throughout Latin America, women have historically been responsible for household supplies of potable water and for maintaining and rationing supplies while overseeing use for sanitation. In countries such as Brazil, Argentina, and Mexico, this customary role in managing water quality, as well as quantity, has led women to take an active role in popular struggles by the poor-usually successful onesto obtain drinking water and sanitation facilities. The authors show that such experience and concern has led women to further expand this role, increasingly seeking professional training, and they argue convincingly that women's participation, as leaders and even policy makers, will be critical in achieving sustainable water use and protecting the natural environment.

The chapter by Boelens and Zwarteveen deals with women's expanding role in irrigation, a fundamental change that is occurring throughout the Andes today, mainly as a necessary adjustment in campesino households where men migrate seasonally, or often for long periods of time, in order to work for wages and acquire much-needed cash. Increasingly, too, peasant communities include divorcées, widows, and single mothers who are heads-of-household, irrigators, and sometimes even members of user groups. Although it is difficult to do justice to the high quality of the discussion (as an overview of irrigation, of the dilemmas of feminist theory in anthropology, and of critiques of "the household"), the chapter comes down to one basic fact about the Andes - the reality of a gender gap in water rights, derived from a more basic gap in rights to land - and the question of whether or not anything should be done about it. Whether land and water are privately owned or held as a form of common property, the legal titles or formally recognized rights of households are usually in the hands of men. This means that women, who in many areas now do most of the irrigation work, have no formal rights and are usually excluded as voting members and as leaders of user groups.

Depending on one's theoretical perspective and ideological commitments, this formal "invisibility," once based on a different division of labor (irrigation being traditionally men's work), reflects the profound 
inequalities and gender-based injustices that are found in most societies (or even the universal subordination of women) and should be eliminated. Or, alternatively, it can be no cause for concern because gender roles in Andean households are highly complementary, so that women are usually consulted and their needs and interests taken into account in water-related decisions made by men. According to the former view, single mothers and female heads-of-household, and women in general, are left out in the cold in terms of access to resources and income as well as political decision making. Meanwhile, the latter holds that, in actual practice (i.e., despite the formal rules), fair access and its benefits are assured to women, including voter representation, either by spouses or by family and community networks of support.

The authors provide a nuanced account of this gender debate, focusing on the discourses and representations involved and the different views of social reality that these produce. They show that Andean women themselves employ competing representations and ideologies in different contexts, using them creatively to pursue various strategic ends: individual rights to water and decision-making power, or funding from an NGO for communal rehabilitation and construction projects. But the authors remain neutral in the debate, implying that different and often ambiguous realities prevail in different places and are ultimately up to local people to straighten out. Given the authors' profound scepticism about "universals" and their views on the limitations of national law, in places where women's interests are not voiced, or are indeed neglected, in decisions about water affairs, such a stance may prove to be an obstacle in their commitment to empowering local user groups while including the excluded.

One of the most revealing contributions to the volume, at least for the purposes of this essay, is Gelles's analysis of the dynamics of resistance against both the State and the World Bank by peasant farmers in the village of Cabanaconde in southern Peru (chap. 2). By providing additional information on outcomes, the chapter provides a necessary complement to his full-length ethnography, and helps to complete the engrossing picture of conflict that he paints there. In Cabanaconde we see a stratified and divided community that nevertheless managed to govern its own commons fairly well, and to deal with a chronic water scarcity, until its members recently took drastic action to increase the supply.

One night in 1983, a small group took matters into their own hands and blew a hole in the Majes canal, one of the biggest hydraulic projects ever carried out by the Peruvian government and the World Bank. They helped themselves to a large flow of water that they had been promised but never given by the project directors, thereby alleviating a severe shortage and setting off a chain reaction of similar daring moves by other indigenous communities in the Colca valley. 
For a long time, the peasant majority has been locked in a struggle against the State, as well as an allied minority of local mestizo elites, to maintain their autonomy in managing this new water and the other water that they already had. They have resisted the imposition of a bureaucratic management structure that is ultimately of foreign origin, one that Gelles refers to as the "de canto" or state model. This more "rational" plan for distribution, supposedly based on Peru's existing water law (it actually comes from a ministry guideline), was used by state officials in the past to unfairly benefit the village's bigger landowners, people of largely Spanish descent, by allowing them to expand irrigation with the six days of water that were saved when the plan was implemented in a sort of "trial run," rather than using the water to increase the frequency of irrigation for everyone in the village, an outcome that is not required by Peru's national law. Thus the village majority, indigenous people and peasants, have resisted the state model and held on to their own, slightly more wasteful one. In the book it remains unclear exactly why the struggle is taking place, but clearly this favoritism, in lieu of a benefit that could have been equitably shared, must be one of the reasons. The two accounts together are impressive in many ways as the story of a successful struggle against domination by outsiders, but they never quite manage to define something that surely must be there, which the people are defending, and that is their concept of equity.

Gelles reveals that 150 liters per second (lps) of water were permanently gained from the Majes Canal as a result of the heroic act of 1983, and used to expand irrigation by reclaiming thirty-six hectares of longabandoned land. The community distributed these among a tiny group of lottery winners, smallholder heads-of-household who received one hectare each. But 150 lps is enough to irrigate far more land; indeed, the article reveals that it is nearly double the amount originally controlled by the community. Later in the chapter we learn that another 350 lps of water was given to Cabanaconde by the Majes Project, contingent on their coming up with a suitable plan for using it, thus bringing the total supply up to $600 \mathrm{lps}$, or roughly six times what the community originally had. Gelles never tells us what was done with the vast majority of this water. Assumedly it was used to benefit the rest of the community by increasing the frequency of irrigation-but where, for whom, and under what arrangement? We are told that, in the end, the village managed to reclaim 1100 abandoned hectares and effectively double its irrigated land base to 2300 hectares. Reading between the lines, we can only assume that the water was also used to increase the irrigation frequency on the lands already in production, those traditionally farmed by the community. Was this done so that all the land, and all the original landowners, benefited? Apparently so; 


\section{Latin American Research Review}

earlier in the article Gelles reveals that the community's original watering cycle of seventy-five to one hundred days before 1983 has been shortened to only forty-five to fifty days today, or roughly cut in half, presumably benefiting all landowners and all lands, since Gelles speaks in terms of "each rotation" and mentions no exceptions.

One is left with the strong impression that the water was ultimately distributed among all the irrigated lands, both old and new, and among all local landowners, proportionally according to the area of each parcel but on the same uniform cycle. In the case of the traditional lands, additional water must have been given in proportion to the extent of each household's original property. The rest must have been allocated according to amount of land people were given for participating in the reclamation project, which itself was probably made proportional to their labor contributions, since that seems to have been the arrangement for similar expansions in most of the other cases analyzed in the volume. This would appear to express the Cabaneños' concept of equity, and reveal in an abstract way the normative framework that now defines their water rights: the principles of uniformity and proportionality. It is important to note that water rights have been defined in this same way in many other Andean communities; again, the definition seems to be manifested within several of the multi-community organizations described in the Mexican anthology. And, although the editors do not attach much significance to this, it is the same basic arrangement arrived at by most of the expanding community and multi-community organizations discussed in the Andean volume: Oruro in Bolivia, and Llicto, Urcuquí, and Ceceles in Ecuador.

This reveals the main problem, indeed the only one, with the position taken by the editors and contributors to the Gelles book. In irrigation and water management, "equity" is not many different things to different people. Water rights, the book's primary focus, have been defined in the same general terms, probably through similar processes of negotiation and confrontation, in a multitude of communities of varying scales throughout Latin America and the world, in situations where people have been allowed to work out their own solutions to the problem of sharing a water scarcity. The local differences that the editors and contributors to the book constantly point to are, when viewed comparatively but within their specific contexts, ones of degree rather than kind. These apparent exceptions seem to prove the rule.

For example, limits on how much land and/or water a family can gain in an expansion project by investing in the communal work, mentioned in chapter 3, can be viewed as a way of ensuring that everyone who contributes to a project can benefit fairly from it. All successful self-managed communities appear to have some kinds of rules or norms that limit the amount of land and/or water a household can 
accumulate. Practically speaking, these have the effect of ensuring that no single user's right to those resources can ever grow so large as to jeopardize the rights and the livelihood of everyone else. And the rights are still proportional within the limits set. The same is true of lower limits that equalize the time that very small plots are irrigated; these are practical measures to ensure that tiny plots get watered sufficiently when there is a relatively large canal flow. Another example, contributions to maintenance work that are the same for all, rather than proportional to each household's land area or their water consumption, were already discussed. Such a democratic arrangement (one household, one vote), is nearly universal in successful, community-based irrigation systems and usually not tied directly to labor contributions, and elsewhere (as in Peru) it is mandated by national water law.

The editors' point is that the "hydraulic property" relations resulting from these improvement projects-the relations between households, their land, and their water, as well as the resulting relations among water-users-are perceived as equitable by the local people themselves. But a strong argument can be made that they can be considered equitable (i.e., uniform and yet proportional) from a practical as well as an objective point of view. These particular, concrete manifestations of "equity" based on local normative frameworks are of a single general kind, one that consists of much more than a post-structuralist "family resemblance." And, although the editors might disagree, that has extremely important implications for resource management policy and for the task of writing new and better national water laws.

The Boelens and Hoogendam volume includes a lengthy discussion (chap. 6 by Boelens, Dourojeanni, Durán, and Hoogendam) of the many challenges involved-legal, politico-economic, organizational, etc.-in devising a new watershed-based plan for decentralized resource management, one that would effectively integrate all the competing uses of water and not just affect irrigation. Although none of the Latin American countries have done this successfully yet, many of them are now trying to in such a way that peasant communities will survive instead of being made extinct by power companies, agribusinesses, and other big water users. In the chapter, and in chapter 9 by Castro-Lucic, we see that the latter is slowly happening today in Chile, with its national water market, and we are shown why. However, throughout the authors' discussion of the various possible new approaches-state-centered, market, consensus-based, and "empowerment" - the role that national water laws can play in establishing equity and sustainability at the local level is said to be important, on the one hand, but extremely limited on the other.

A weakness of the book, and the chapter on plans for decentralized management, is its failure to include an examination of the content of 


\section{4}

Latin American Research Review

any water law other than Chile's, which the World Bank has used as a model in its unsuccessful effort to impose privatization on people throughout the hemisphere. In Peru, Ecuador, and Bolivia, a discussion of water laws would be revealing because the laws seem to be essentially the same, evidently based on a single model imported from landgrant research institutions in the United States. The editors and contributors to the book correctly point out that most communities in the Andes have implemented these laws only selectively, if at all, creatively modifying the provisions and requirements according to their own normative frameworks and their own customary law. Indeed, a better illustration of the processes of "agency" and "structuration" could scarcely be found than the one presented here. They speak, however, as if this were invariably true, suggesting that, due to the weakness of the Andean states, the laws have had little impact in the Andean countryside and have never been fully implemented anywhere. This is simply not true. In Peru, for example, the General Water Law (the basis of Gelles's "state model") was a lynchpin of the 1969 agrarian reform and was widely implemented, generally in the former centers of hacienda domination, the provincial capitals and major highland towns, where it created serious conflict, both within local communities and between them. The problems arose, not from any rigidity or excessive specificity in the law, as the editors would expect, but rather from its vagueness, which local power brokers have been able to exploit to their own benefit and the detriment of the majority.

To the book's contributors, these laws are one-size-fits-all legislation designed to impose strict equality on all communities and all water users, through provisions requiring that rights be explicitly defined in exactly the same way, based on ethnocentric concepts like proportionality in the land/water ratio. In actual practice, nothing could be further from the truth. The General Water Law, like its counterparts in the adjacent countries, is based on a technocratic and agronomic model for irrigation according to which it is the needs of crops that are being met, rather than those of people, and water allocation is therefore too complex and dynamic a task for local people to oversee. Furthermore, because of this agronomic and hydrological complexity, the law fails to assert any basic proportionality or even comparability among individual users' rights to a given water source, either in terms of quantity or frequency of use. It leaves them subject to a highly technical process of calculation and dispersal that, because highland communities lack the necessary facilities and equipment, never gets carried out in practice. The result, in the many places where the law has been implemented, either partially or fully, is a morass of vaguely defined and highly unequal rights (both individual and communal in multi-community systems) that foster waste, corruption, and conflict, and promote water scarcity. The flexible and opaque 
system of allocation that such laws have created in practice is one that local elites and large landowners have been able to manipulate and dominate, trampling on the rights of the poorer majority and excluding other people from much of the real decision-making (certainly all women), just as they have done in the past.

In one of his chapters, Boelens sums up his final judgement on the relevance of these national water laws to local practice:

[It is] a moot point to grant weight and importance to the many attempts to discover and describe "the best principles, rules, and rights" - even universal prescriptions-to norm the management of water and other natural resources. The inconsistency and mistakes of instrumental thinking mean that we must not concentrate just on the articulation of rules or on the formal and informal contents of regulatory norms [emphasis his], but also on the processes of constructing them, and on their use and modification in particular practice. (165)

With the latter statement I could hardly agree more, but I strongly disagree with the former, and the two judgements contradict each other in any case. We must, of course, always focus on the actual use of rules in social practice, since, as the book's contributor's never fail to point out, the mere existence of a rule provides no guarantee that it will be respected or enforced. But some rules are better than others, being more easily agreed upon and more easily enforced. What are we to do about the contents of national water legislation, particularly when the same concept of equity has emerged again and again throughout the world in peasant customary law? Perhaps this principle can be used as the basis or model for better national water laws, ones that will promote the creation of equity by empowering local organizations to achieve it on their own, including all deserving water users and without having to depend on the largesse and dedication of an NGO. Despite the extraordinary work done by these organizations and their personnel, which we see laid out so impressively in the Boelens and Hoogendam volume, most communities in the Andes do not have such assistance and cannot realistically expect to receive it in the near future. How can they be "included"?

What can be done with the existing laws except see that they are amended or replaced? As the contributors to the Andean volume admit without elaborating on the point, the Latin American countries cannot do without legislation, even in decentralized, watershed-based systems of management. Unless governments surrender completely to the free market, the State will have to provide some kind of legal framework within which local struggles for autonomy, and equity will continue to take place. In Ecuador, Bolivia, and Peru, the Andean people have risen up in the most extraordinary and successful anti-globalization protest the world has seen yet, repelling the Bank's assault on their sovereignty and shouting a collective and non-negotiable "no" to 


\section{Latin American Research Review}

water privatization. Thus the will to resist the neoliberal juggernaut is clearly present, but this "Fourth World" movement seems to lack a welldefined alternative proposal around which it can really coalesce-a situation that emerging populist governments in the region would be wise to turn to their advantage. This could be done in such a way as to give the communities and their various interest groups sufficient room to maneuver, but not without asserting general principles that require rights to have some kind of symmetry, provisions that limit them and make them comparable to each other in some basic way. Who will decide upon the latter, choosing among alternatives and sorting out the virtues and defects of the various new law projects that have been proposed? Governments and elected representatives, of course, but hopefully this time they will consider all serious proposals, not just ones written by economists and lawyers hired by the World Bank. After reading this volume, one cannot help but wonder what kind of proposal the contributors could come up with, as knowledgeable and skilled a group of "experts" and practitioners as has ever been brought together in one place. Now that they have shown themselves to be uniquely qualified, I expect to see this happen, and look forward to seeing the result. 